\title{
Tele-pathology in plants for disease diagnosis in agriculture: Review and analysis
}

\author{
Gyan Vardhan Singh* and Pooja Singh
}

Department of Electronics and Communication Engineering, Amity University, Lucknow Campus, Lucknow (U.P.) India

\section{ARITCLE INFO \\ Received : 24.07.2019 \\ Accepted : 28.09.2019}

\section{KEY WORDS :}

Artificial intelligence, Tele-pathology, Neural Networks, Image based plant disease identification

*Corresponding author:

Email : singh.gyanvardhan@gmail.com

\begin{abstract}
Early diagnosis of diseases play a crucial role in increasing the agricultural productivity and ensuring food security. Specially, in many parts of the world, immediate disease identification remains difficult due to the lack of necessary infrastructure. Besides that, many challenges are noticed to identify the plant diseases correctly such as multiple and simultaneous disorders in a single plant, different disorders having similar symptoms etc. In spite of all the challenges, deep learning approaches have shown promise in classifying the complex diseases correctly. As digital India is advancing, smart agricultural systems will provide assistance to farmers, and "Tele-pathology in plants" is the way forward. In this context, a literature review on classification of different kinds of approaches and techniques has been presented with the objective focus on designing an inclusive system architecture for Tele-pathology in plants. Discreet studies focusing on specific verticals are present among the research community but a holistic structural approach formalizing the use cases is missing. The purpose of this research is to propose and explain a system architecture with interplay among different system blocks such as crop disease imagedataset, annotation of digital image dataset by consultation with the domain expert, generation of disease markers and establishing different algorithmic techniques.
\end{abstract}

How to view point the article : Singh, Gyan Vardhan and Singh, Pooja (2019). Tele-pathology in plants for disease diagnosis in agriculture: Review and analysis. Internat. J. Plant Protec., 12(2) : 183-187, DOI : 10.15740/HAS/IJPP/12.2/183-187, Copyright@ 2019: Hind Agri-Horticultural Society. 